\title{
New Gene for Bacterial Blight Resistance in Rice Located on Chromosome 12 Identified from Minghui 63, an Elite Restorer Line
}

\author{
Huilan Chen, Shiping Wang, and Qifa Zhang
}

National Key Laboratory of Crop Genetic Improvement, Huazhong Agricultural University, Wuhan 430070, China. Accepted for publication 28 February 2002.

\begin{abstract}
Chen, H., Wang, S., and Zhang, Q. 2002. New gene for bacterial blight resistance in rice located on chromosome 12 identified from Minghui 63, an elite restorer line. Phytopathology 92:750-754.

Bacterial blight, caused by Xanthomonas oryzae pv. oryzae, is a serious disease of rice worldwide. A new dominant gene for bacterial blight

oryzae in both seedling and adult stages. It was mapped to the centromeric region of chromosome $12,2.5 \mathrm{cM}$ from a disease resistance genehomologous sequence, NBS109, and $7.3 \mathrm{cM}$ from a restriction fragment length polymorphism marker, G1314. The genomic location of this gene is similar to the previously identified blast resistance genes, $P i$-ta and Pi-ta2.
\end{abstract} resistance in rice, $X a 25(\mathrm{t})$, was identified from Minghui 63, a restorer line for a number of rice hybrids that are widely cultivated in China. This gene conferred resistance to Philippine race 9 (PXO339) of X. oryzae pv.
Additional keywords: mapping, $R$ gene.
Bacterial blight, caused by Xanthomonas oryzae pv. oryzae, is one of the most destructive diseases of rice worldwide. Numerous major genes with resistance to various strains of $X$. oryzae pv. oryzae have been identified, which have been named in a series from Xal to Xa24 $(9,10,12,25)$. More than 10 bacterial blight resistance $(R)$ genes are mapped on rice chromosomes 4 (Xal, $X a 2, X a 12$, and Xa14), 5 (xa5), 6 (Xa7), 8 (xa13), and 11 (Xa3, $X a 4, X a 10, X a 21, X a 22$, and $X a 23)$, with some of the genes being allelic or tightly linked with each other $(9,10,12,25)$. The chromosomal locations for the rest of the bacterial blight resistance genes are still unknown.

More than 30 plant $R$ genes have now been cloned. Most of the cloned $R$ genes encode 1 to 3 recognizable structural domains, including leucine zipper (LZ), Toll-IL-1R homology region (TIR), nucleotide-binding site (NBS), leucine-rich repeat (LRR), and protein kinase (3). Four $R$ genes, Xa21, Xal, Pi-b, and Pi-ta, have been isolated from rice. The bacterial blight resistance genes Xa21 and $\mathrm{Xal}$ encode the LRR-kinase protein and the NBS-LRR protein, respectively $(16,22)$, and the blast resistance genes $P i-b$ and $P i$-t $a$ encode NBS-LRR type proteins $(1,19)$.

Minghui 63 is the male parent for a number of widely used hybrids in rice production in China. It also is called a restorer line because it restores the fertility of the $\mathrm{F}_{1}$ hybrid after crossing with a male-sterile line. The major characteristics of the hybrids produced with Minghui 63 are high yield and wide adaptability, which enable these hybrids to occupy more than $20 \%$ of the total rice production area in China for the last 20 years. The wide adaptability of these hybrids is due in part to the resistance of Minghui 63 to bacterial blight, one of the most serious diseases of rice in south China. Previous study indicated that Minghui 63 carries a dominant gene located on chromosome 11 for resistance to a Chinese strain of X. oryzae pv. oryzae, JL691 (17). In a screen of Minghui 63 to the Philippine isolates of $X$. oryzae pv. oryzae,

Corresponding author: S. Wang; E-mail address: swang @mail.hzau.edu.cn

Publication no. P-2002-0422-03R

(c) 2002 The American Phytopathological Society we found that this rice cultivar was also incompatible with strain PXO339. This suggests that Minghui 63 may carry other bacterial blight resistance genes responsible for its enduring resistance. The objectives of this study were to determine if Minghui 63 carries any unknown bacterial blight resistance gene or genes, and to characterize them.

\section{MATERIALS AND METHODS}

Mapping population. A population of recombinant inbred lines (RILs) of rice was used in this study. This population consisted of 241 lines developed by single-seed descendent from a cross between Zhenshan 97 (Oryza sativa subsp. indica) and Minghui 63 (O. sativa subsp. indica), the parents of Shanyou 63, the most widely used hybrid in China. A molecular linkage map containing 221 loci and covering $1,790 \mathrm{cM}$ was constructed with this population (20).

Pathogen inoculation and disease evaluation. For adult plant inoculation, 11 seedlings of each RIL, Zhenshan 97, and Minghui 63 were planted in single rows spaced $26.4 \mathrm{~cm}$ apart. Plants were spaced $16.5 \mathrm{~cm}$ apart in the row. At the booting stage (approximately 40 days after transplanting), 6 to 10 of the uppermost fully expanded leaves of each plant were inoculated with the $X$. oryzae pv. oryzae strains (Table 1) by the leaf clipping method (12). For disease scoring, nine plants in the middle of each row were evaluated 3 weeks after inoculation. Four leaves with the longest lesion from each of the nine plants were selected for analysis by measuring the lesion length and leaf length. The lesion area (percent) was obtained by dividing the lesion length (centimeters) by the leaf length.

For seedling stage inoculation, 10 seedlings each of Zhenshan 97 and Minghui 63 were planted in a greenhouse. The seedlings were inoculated with the $X$. oryzae pv. oryzae strains at the three to four-leaf stage by the same method used for the adult plants and were scored for disease 2 weeks later (Table 1).

Data analysis. The lesion lengths of the plants after $X$. oryzae pv. oryzae inoculation frequently were influenced by environment. Therefore, the value at the valley of the distribution of lesion 
length, instead of a fixed value, was used as the dividing point for classifying plants into resistant and susceptible groups in a segregation population. The chromosomal location of the bacterial blight resistance gene on the molecular linkage map was determined by using Mapmaker/Exp 3.0 with an LOD threshold of 3.0 (13).

\section{RESULTS}

Resistance of experimental materials to $X$. oryzae pv. oryzae strains. One of the parents of the RILs, Minghui 63, was highly resistant to PXO339 and JL691 and moderately resistant to PXO112 and T7147 at the adult plant stage; Minghui 63 also was highly resistant to PXO339 and JL691 and moderately resistant to PXO112 at the seedling stage (Table 1). The other parent of the RILs, Zhenshan 97, was susceptible to all of the $X$. oryzae pv. oryzae strains tested at both adult and seedling stages (Table 1).

To identify whether the resistance of Minghui 63 to $X$. oryzae pv. oryzae strain PXO339 was conferred by any previously identified $R$ genes, five near-isogenic lines for bacterial blight resistance (IRBB4, IRBB5, IRBB7, IRBB10, and IRBB14 carrying Xa4, $x a 5, X a 7, X a 10$, and $X a 14$, respectively), together with their recurrent susceptible parent, IR24, were examined for resistance to PXO339 at the adult plant stage. These near-isogenic lines showed average lesion lengths of $4.4 \mathrm{~cm}$ (IRBB4), $11.4 \mathrm{~cm}$ (IRBB5), $0.7 \mathrm{~cm}$ (IRBB7), $12.8 \mathrm{~cm}$ (IRBB10), $10.6 \mathrm{~cm}$ (IRBB14), and $10.5 \mathrm{~cm}$ (IR24) 3 weeks after inoculation with PXO339, indicating that two genes, $\mathrm{Xa} 4$ and $\mathrm{Xa}$, located on chromosomes 11 and 6, respectively, were incompatible with PXO339.

The segregation patterns of the resistance to PXO339 in the RIL and $\mathbf{F}_{2}$ populations. The distribution of lesion length for PXO339 infection in the RIL population was bimodal with an apparent valley at approximate $6 \mathrm{~cm}$ in the year 1999 (Fig. 1A). Because of the difference in the leaf length between Zhenshan 97 and Minghui 63, the lesion area also was used as a criterion to evaluate the resistance of the RILs to PXO339 infection. The lesion area showed a distribution pattern similar to that of the lesion length (Fig. 1B), and the two measurements were highly correlated $(r=0.962)$. Using a lesion length of $6 \mathrm{~cm}$ as the dividing point, the numbers of resistant and susceptible lines in the RIL population were 115 and 126, respectively, and fit the expected $1: 1$ ratio $\left(\chi^{2}=0.502, P>0.25\right)$, indicating the involvement of a major gene for resistance to PXO339.

We also investigated the resistance reaction of Minghui 63 to PXO339 using an $F_{2}$ population of 1,187 individuals from the same cross in year 2000. The distribution of the lesion length in the $F_{2}$ population also appeared to be bimodal. The numbers of resistant (875) and susceptible (312) plants fit the expected 3:1 ratio $\left(\chi^{2}=0.944, P>0.25\right)$ if $10 \mathrm{~cm}$ in the apparent valley was used as the dividing point (Fig. 2). These results suggested that the resistance of Minghui 63 to PXO339 was controlled by a single dominant gene.

Molecular mapping of the major gene conferring resistance to PXO339. Using the lesion length of the RILs as the criterion, the gene for resistance to PXO339 was mapped to the centromeric region of chromosome 12 , located between restriction fragment length polymorphism (RFLP) markers R887 and G1314 (Fig. 3A). No bacterial blight resistance gene previously has been mapped to
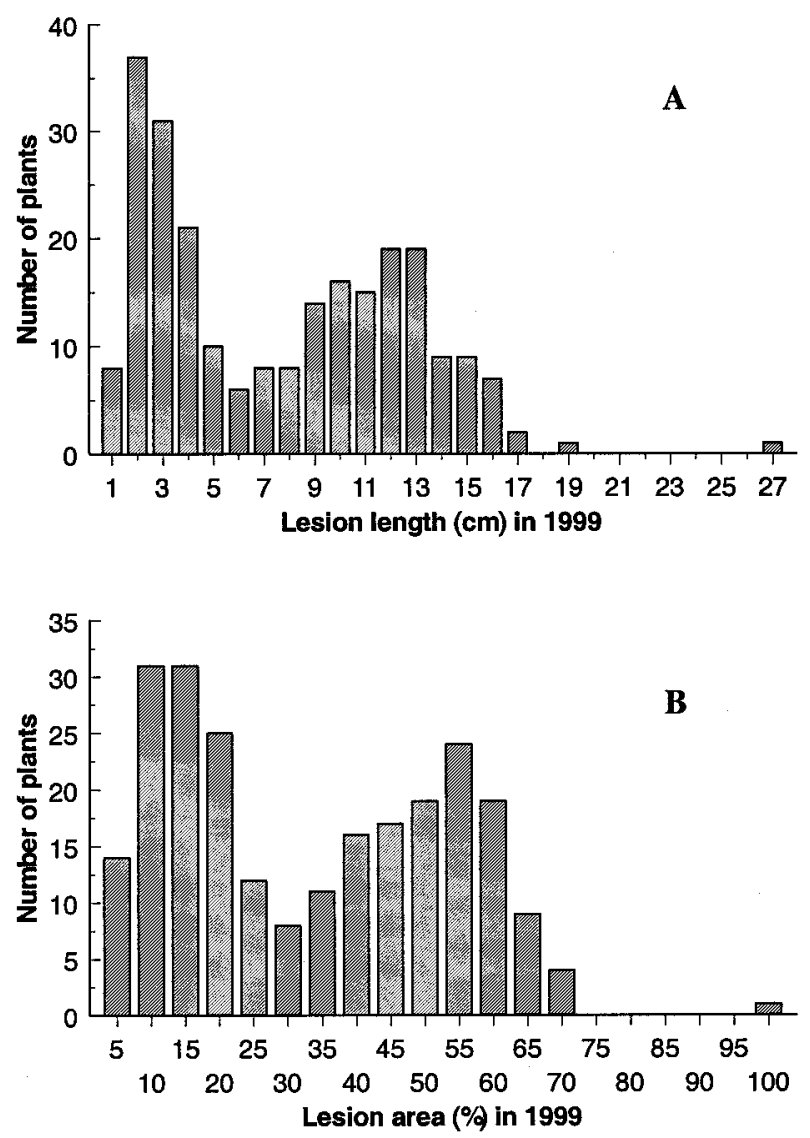

Fig. 1. Distribution of $\mathbf{A}$, lesion length and $\mathbf{B}$, lesion area after PXO339 inoculation in the recombinant inbred line population derived from the cross between Zhenshan 97 and Minghui 63.

TABLE 1. Lesion lengths $(\mathrm{cm})$ of the parents of recombinant inbred lines after inoculation with Xanthomonas oryzae pv. oryzae

\begin{tabular}{|c|c|c|c|c|}
\hline \multirow[b]{2}{*}{ Strain } & \multicolumn{2}{|c|}{ Booting stage } & \multicolumn{2}{|c|}{ Seedling stage } \\
\hline & Zhenshan 97 & Minghui 63 & Zhenshan 97 & Minghui 63 \\
\hline \multicolumn{5}{|l|}{ Philippine strains } \\
\hline PXO79 (race 3) & 21.2 & 21.3 & 11.8 & 11.8 \\
\hline PXO71 (race 4) & 20.2 & 13.3 & 11.9 & 13.7 \\
\hline PXO112 (race 5) & 8.9 & 6.3 & 10.2 & 5.3 \\
\hline PXO280 (race 8) & 17.5 & 21.0 & 7.9 & 8.7 \\
\hline PXO339 (race 9) & 20.6 & 0.9 & 7.5 & 1.6 \\
\hline \multicolumn{5}{|l|}{ Chinese strains } \\
\hline JL691 & 22.0 & 1.0 & 8.9 & 0.7 \\
\hline LN44 & 20.2 & 7.5 & $\ldots$ & $\ldots$ \\
\hline Zhe173 & 15.7 & 9.4 & 14.3 & 9.6 \\
\hline \multicolumn{5}{|l|}{ Japanese strains } \\
\hline
\end{tabular}


this location; therefore, the gene against PXO339 in Minghui 63 is a new $R$ gene in the sense that no known gene for bacterial blight resistance has been mapped to this chromosome. We tentatively designate this new gene as $\mathrm{Xa25}(\mathrm{t})$.

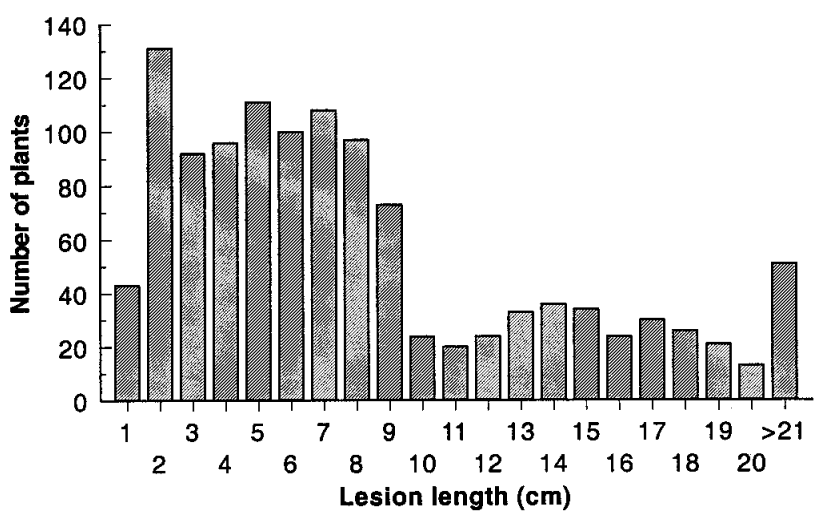

Fig. 2. Distribution of lesion length after PXO339 inoculation of an $\mathrm{F}_{2}$ population derived from the cross between Zhenshan 97 and Minghui 63.

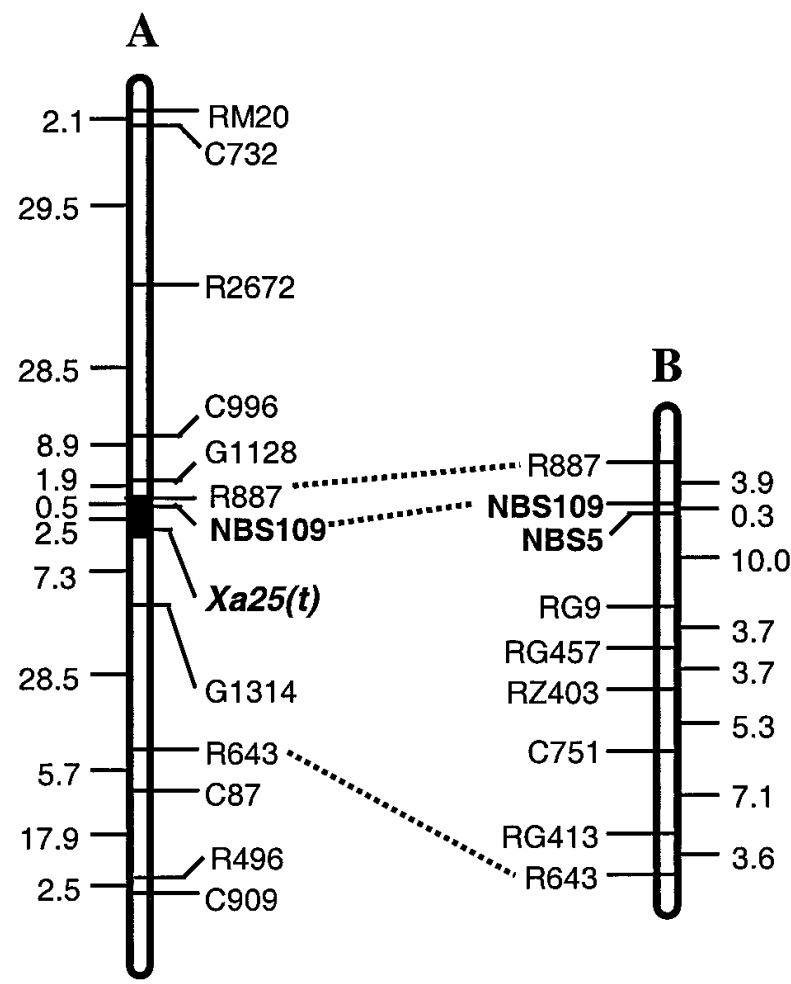

Fig. 3. The location of $X a 25(\mathrm{t})$ gene and nucleotide-binding site (NBS) sequences on the molecular linkage maps of chromosome 12. The maps were based on the recombinant inbred line population from A, Zhenshan 97Minghui 63 and $\mathbf{B}$, the $F_{2}$ population from Aijiao Nante-P16. The solid black box in map A represents the relative location of the centromeric region according to the mapping information of Wang et al. (18).
To take a candidate gene approach to the $X a 25(\mathrm{t})$ locus, two clones from rice, NBS109 and NBS5, that were previously mapped to this chromosomal region (M. A. Saghai Maroof, unpublished data) and contained sequences homologous to the NBS domain of disease resistance genes, were used as probes to test their cosegregation with $\mathrm{Xa25}(\mathrm{t})$. Only NBS109 detected polymorphism between the two parents by RFLP analysis and was located at a distances of $2.5 \mathrm{cM}$ from $\mathrm{Xa25}(\mathrm{t})$ and $0.5 \mathrm{cM}$ from R887 (Fig. 3A). The new gene, therefore, is flanked by molecular markers NBS109 and G1314 with an estimated genetic distance of $2.5 \mathrm{cM}$ from NBS109 and $7.3 \mathrm{cM}$ from G1314. A rice population consisting of $172 \mathrm{~F}_{2}$ individuals derived from a cross between cv. Aijiao Nante (O. sativa subsp. indica) and a common wild rice $(O$. rufipogon), P16, was also used to map the two NBS sequences. A molecular linkage map based on this $\mathrm{F}_{2}$ population contained 612 loci (21). Both NBS109 and NBS5 detected polymorphism between the parents of the $\mathrm{F}_{2}$ population and the two sequences were closely linked in the centromeric region of chromosome 12 (Fig. 3B).

Resistant spectrum of $\mathrm{Xa25(t)}$. It is known that the gene in Minghui 63 for resistance to JL691 is located on chromosome 11 (17). In order to separate the effects of $X a 25(t)$ from the one on chromosome 11, we determined the approximate location of the resistance gene on chromosome 11 using the RIL population, which was in the terminal region of the long arm of chromosome 11 flanked by RFLP markers L1044 and Y6855RA (Fig. 4). Because several other genes for bacterial blight resistance (e.g., Xa3, Xa4, Xa22, and Xa23) $(12,14,23,25)$ also were located in this region, its relationship with these genes remained to be determined.

Five RILs were selected on the basis of molecular genotypes in these two regions (Table 2). Two RILs (R4 and R128) had Zhenshan 97 genotypes at the unnamed resistance locus on chromosome 11, thus carrying the susceptible allele of this locus, and had Minghui 63 genotypes in $X a 25(\mathrm{t})$ region, thus carrying the resistant allele of this locus. The other three RILs (R19, R20, and $\mathrm{R} 202$ ) had exactly the reverse genotypes in the two regions. The five lines and their parents were inoculated with $11 \mathrm{X}$. oryzae pv.

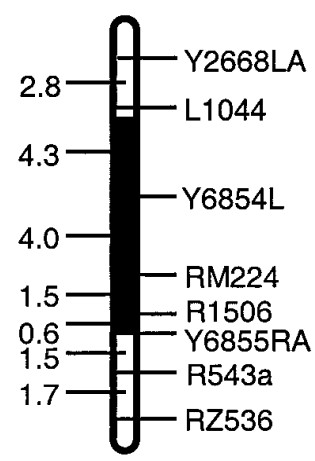

Fig. 4. The location of a bacterial blight resistance gene against Xanthomonas oryzae pv. oryzae strain JL691 in chromosome 11. The solid box indicates the chromosomal region containing the unnamed resistance gene.

TABLE 2. The genotypes of five selected recombinant inbred lines on the chromosomal regions containing bacterial blight resistance genes ${ }^{\mathrm{a}}$

\begin{tabular}{|c|c|c|c|c|c|c|c|c|}
\hline \multirow[b]{2}{*}{ Rice line } & \multicolumn{5}{|c|}{ Markers across the region containing the unnamed $R$ gene on chromosome 11} & \multicolumn{3}{|c|}{ Markers across the $X a 25(\mathrm{t})$ region } \\
\hline & L1044 & Y6854L & RM224 & $\mathrm{R} 1506$ & Y6855RA & $\mathrm{R} 887$ & NBS109 & G1314 \\
\hline R4 & $\mathrm{Z}$ & $\mathrm{Z}$ & $\mathrm{Z}$ & $\mathrm{Z}$ & $\mathrm{Z}$ & M & M & M \\
\hline R128 & $\mathrm{Z}$ & $\mathrm{Z}$ & $\mathrm{Z}$ & $\mathrm{Z}$ & $\mathrm{Z}$ & M & M & M \\
\hline R19 & M & M & M & M & M & Z & Z & Z \\
\hline R20 & M & M & M & M & M & Z & $\mathrm{Z}$ & Z \\
\hline R202 & $\mathrm{Z}$ & M & M & M & M & Z & $\mathrm{Z}$ & Z \\
\hline
\end{tabular}

${ }^{\text {a }} \mathrm{Z}=$ homozygous for Zhenshan 97 and $\mathrm{M}=$ homozygous for Minghui 63. 
oryzae strains, including 7 Philippine strains (PXO61, PXO86, PXO79, PXO71, PXO112, PXO280, and PXO339), 2 Chinese strains (JL691 and ZJ173), and 2 Japanese strains (T7133 and T7147) at seedling and booting stages in 2001.

At the seedling stage, RILs carrying $X a 25(\mathrm{t})$ appeared to be resistant to strain PXO339, whereas those carrying the unnamed $R$ gene on chromosome 11 were susceptible to PXO339 (data for three of the strains are given in Table 3). All five RILs were resistant to strain JL691 but with the lesions two to three times as long as that of Minghui 63, suggesting that the two genes enhanced each other in the resistance of Minghui 63 to JL691 (Table 3). All five RILs also showed partial resistance to PXO112, which is approximately the same level of resistance as found in Minghui 63 (Table 3). Thus, the absence of either of the two genes did not influence the resistance to PXO112.

At booting stage, lines R4 and R128 still were resistant to PXO339 but became susceptible to JL691 (Table 3). The other three RILs were resistant only to JL691. These results suggest that $\mathrm{Xa25}(\mathrm{t})$ was resistant to PXO339 at both seedling and adult stages, and resistant to JL691 at the seedling stage but not the adult stage. The results also indicated that the unnamed $R$ gene on chromosome 11 had no effect on the resistance to PXO339 at either seedling or adult stage.

\section{DISCUSSION}

The present study identified a new dominant gene, $X a 25(\mathrm{t})$, for bacterial blight resistance in Minghui 63, a restorer line for a number of widely used hybrids in rice production in China. The new gene conferred resistance in Minghui 63 to the $X$. oryzae pv. oryzae strain PXO339 at both seedling and adult stages. This gene also partly contributed to the resistance of Minghui 63 to a Chinese X. oryzae pv. oryzae strain, JL691, at seedling stage. The resistance of the unnamed gene on chromosome 11 appeared to affect only one $X$. oryzae pv. oryzae strain; therefore, it is reasonable to assume that $X a 25(\mathrm{t})$ has made a major contribution to the resistance of the hybrids in the last 2 decades.

A number of rice $R$ genes previously were mapped to chromosome 12 and all of them conferred resistant to blast. Among these genes, $P i$-ta and $P i$ - $t a^{2}$ have been identified as being allelic or tightly linked with each other and located on the centromeric region corresponding to the location of $\mathrm{Xa25}(\mathrm{t})$ determined in this study $(1,15)$. There also were a number of blast resistance genes, including $P i-4^{\mathrm{a}}(t), P i-4^{\mathrm{b}}(t), P i-6(t), P i-12(t), P i-19$, and $\mathrm{Pi}-20$ (6$8,24,26)$, that also were mapped to the centromeric region of chromosome 12. A tightly linked cluster containing at least seven blast resistant genes was mapped in the same region as Pi-ta and

TABLE 3. Lesion lengths $(\mathrm{cm})$ of the five selected recombinant inbred lines and the parents after Xanthomonas oryzae pv. oryzae inoculation in 2001

\begin{tabular}{lccc}
\hline & \multicolumn{3}{c}{ X. oryzae pv. oryzae strain } \\
\cline { 2 - 4 } Rice line & JL691 & PXO339 & PXO112 \\
\hline Seedling stage & & & \\
R4 & 2.2 & 1.8 & 5.8 \\
R128 & 1.9 & 1.9 & 3.9 \\
R19 & 1.4 & 9.5 & 5.8 \\
R20 & 1.9 & 7.5 & 3.2 \\
R202 & 1.4 & 4.5 & 6.6 \\
Zhenshan 97 & 8.9 & 7.5 & 10.2 \\
Minghui 63 & 0.7 & 1.6 & 5.3 \\
Booting stage & & & \\
R4 & 8.5 & 4.6 & $\ldots$ \\
R128 & 18.1 & 2.4 & $\ldots$ \\
R19 & 2.3 & 11.1 & $\ldots$ \\
R20 & 1.8 & 10.8 & $\ldots$ \\
R202 & 0.8 & 8.5 & $\ldots$ \\
Minghui 63 & 0.9 & 1.0 & $\ldots$ \\
Zhenshan 97 & 9.4 & 11.0 & $\ldots$ \\
\hline
\end{tabular}

$P i-t a^{2}$ (2). These results suggest that there is at least one multiple gene family for disease resistance in the centromeric region of chromosome 12.

$P i$-t $a$ encodes the NBS-LRR type protein (1). The present study also located two closely linked NBS sequences to the centromeric region of chromosome 12 . R proteins containing NBS motif also have the LRR motif according to the structures of cloned $R$ genes; this suggests that there is at least one NBS-LRR type multiplegene family in the centromeric region of chromosome 12 . Different copies of genes in the multiple- $R$-gene family or the alleles of $R$ loci are commonly the sources for the diversity of recognition specificity in plant resistance to pathogen infection. The L locus of flax contains a single gene of TIR-NBS-LRR type, and 11 alleles with different specificities of resistance to rust fungi have been identified $(5,11)$. The $P$ and $P 2$ genes against flax rust are allelic or tightly linked in the locus containing the TIR-NBS-LRR type multiple-gene family. The two genes encode proteins that differ by 10 amino acids (aa), but only 6 aa changes are sufficient to alter $P 2$ to the $P$ resistant specificity (4). Therefore, the different specificities of blast resistance identified in the loci of centromeric region of rice chromosome 12 by previous studies may contribute to the allelic or tightly linked copies of the genes in the multiple gene family. There were two possibilities regarding the origin and the identity of $X a 25(\mathrm{t})$. One possibility is that the identified $\mathrm{Xa25}(\mathrm{t})$ is a mutant in one of the blast resistance loci, thus being allelic with one or more of the blast resistance genes. The other possibility is that it is at a locus tightly linked to the abovementioned blast resistance loci. Resolving the two possibilities will provide a good opportunity for studying recognition specificity of resistance genes with bacterial blight and fungal blast.

\section{ACKNOWLEDGMENTS}

This study was supported in part by a grant from the National Natural Science Foundation of China and a grant from the National Key Program on Basic Research and Development of China (973). We thank M. A. Saghai Maroof of Virginia Polytechnic Institute and State University for providing rice NBS clones and the International Rice Research Institute for the near-isogenic lines of bacterial blight resistance and the Philippine strains of $X$. oryzae pv. oryzae.

\section{LITERATURE CITED}

1. Bryan, G. T., Wu, K.-S., Farrall, L., Jia, Y., Hershey, H. P., McAdams, S. A., Faulk, K. N., Donaldson, G. K., Tarchini, R., and Valent, B. 2000. A single amino acid difference distinguishes resistant and susceptible alleles of the rice blast resistance gene Pi-ta. Plant Cell 12:2033-2045.

2. Chao, C. T., Moldenhauer, K. A. K., and Ellingboe, A. H. 1999. Genetic analysis of resistance/susceptibility in individual F3 families of rice against strains of Magnaporthe grisea containing different genes for avirulence. Euphytica 109:183-190.

3. Dangl, J. L., and Jones, J. D. 2001. Plant pathogens and integrated defense responses to infection. Nature 411:826-833.

4. Dodds, P. N., Lawrence, G. J., and Ellis, J. G. 2001. Six amino acid changes confined to the leucine-rich repeat $\beta$-strand/ $\beta$-turn motif determine the difference between the $P$ and $P 2$ rust resistance specificities in flax. Plant Cell 13:163-178.

5. Ellis, J. G., Lawrence, G. J., Luck, J. E., and Dodds, P. N. 1999. Identification of regions in alleles of the flax rust resistance gene $\mathrm{L}$ that determine differences in gene-for-gene specificity. Plant Cell 11:495-506.

6. Imbe, T., Oba, S., Yanoria, M. J. T., and Tsunematsu, H. 1997. A new gene for blast resistance in rice cultivar, IR24. Rice Genet. Newsl. 14:6062.

7. Inukai, T., Nelson, R. J., Zeigler, R. S., Sarkarung, S., Mackill, D. J., Bonman, J. M., Takamure, I., and Kinoshita, T. 1994. Allelism of blast resistance genes in near-isogenic lines of rice. Phytopathology 84:12781283.

8. Iwata, N. 1997. Report of the committee on gene symbolization, nomenclature and linkage groups. Rice Genet. Newsl. 14:9-22.

9. Kinoshita, T. 1994. Report of the committee on gene symbolization, nomenclature and linkage groups. Rice Genet. Newsl. 11:8-22.

10. Kinoshita, T. 1995. Report of committee on gene symbolization, nomenclature and linkage groups. Rice Genet. Newsl. 12:9-153. 
11. Lawrence, G. J., Finnegan, E. J., Ayliffe, M. A., and Ellis, J. G. 1995. The $L 6$ gene for flax resistance is related to the Arabidopsis bacterial resistance gene Rps 2 and the tobacco viral resistance gene $N$. Plant Cell 7:1195-1206.

12. Lin, X. H., Zhang, D. P., Xie, Y. F., Gao, H. P., and Zhang, Q. 1996. Identifying and mapping a new gene for bacterial blight resistance in rice based on RFLP markers. Phytopathology 86:1156-115.

13. Lincoln, S., Daly, M., and Lander, E. 1992. Constructing Genetic Maps with Mapmaker/Exp 3.0. 3rd ed. Whitehead Institute Technical Report, Cambridge, MA.

14. Petpisit, V., Khush, G. S., and Kauffman, H. E. 1977. Inheritance of resistance to bacterial blight in rice. Crop Sci. 17:551-554.

15. Rybka, K., Miyamoto, M., Ando, I., Saito, A., and Kawasaki, S. 1997. High resolution mapping of the indica-derived rice blast resistance genes. II. Pi-ta ${ }^{2}$ and $P i-t a$ and a consideration of their origin. Mol. PlantMicrobe Interact. 10:517-524.

16. Song, W.-Y., Wang, G.-L., Chen, L.-L., Kim, H.-S., Pi, L.-Y., Holsten, T., Gardner, J., Wang, B., Zhai, W.-X., Zhu, L.-H., Fauquet, C., and Ronald, P. 1995. A receptor kinase-like protein encoded by the rice disease resistance gene, $\mathrm{Xa21}$. Science 270:1804-1806.

17. Tan, Y. F. 1998. Molecular marker-based genetic analysis of some important traits for improvement of Shanyou 63, an elite rice hybrid. (In Chinese.) Ph.D. thesis. Huazhong Agricultural University, China.

18. Wang, S., Wang, J., Jiang, J., and Zhang, Q. 2000. Mapping of centromeric regions on the molecular linkage map of rice (Oryza sativa L.) using centromere-associated sequences. Mol. Gen. Genet. 263:165-172.

19. Wang, Z.-X., Yano, M., Yamanouchi, U., Iwamoto, M., Monna, L., Hayasaka, H., Katayose, Y., and Sasaki, T. 1999. The Pib gene for rice blast resistance belongs to the nucleotide binding and leucine-rich repeat class of plant disease resistance genes. Plant J. 19:55-64.

20. Xing, Y. Z., Tan, Y. F., Hua, J. P., Sun, X. L., Xu, C. G., and Zhang, Q. Characterization of the main-effects, epistatic effects and their environmental interactions of QTLs in the genetic basis of yield traits in rice. Theor. Appl. Genet. In press.

21. Xiong, L., Wang, S., Liu, K. D., Dai, X. K., Saghai Maroof, M. A., Hu, J., and Zhang, Q. 1998. Distribution of simple sequence repeat and AFLP markers in molecular linkage map of rice. Acta Bot. Sin. 40:605-614.

22. Yoshimura, S., Yamanouchi, U., Katayose, Y., Toki, S., Wang, Z.-X., Kono, I., Kurata, N., Yano, M., Iwata, N., and Sasaki, T. 1998. Expression of $\mathrm{Xa1}$, a bacterial blight-resistance gene in rice, is induced by bacterial inoculation. Proc. Natl. Acad. Sci. USA 95:1663-1668.

23. Yoshimura, S., Yoshimura, A., Iwata, N., McCouch, S. R., Abenes, M. L., Baraoidan, M. T., Mew, T. W., and Nelson, R. J. 1995. Tagging and combining bacterial blight resistance gene in rice using RAPD and RFLP markers. Mol. Breed. 1:375-387.

24. Yu, Z. H., Mackill, D. J., Bonman, J. M., McCouch, S. R., Guiderdoni, E., Notteghem, J. L., and Tanksley, S. D. 1996. Molecular mapping of genes for resistance to rice blast (Pyricularia grisea Sacc.). Theor. Appl. Genet. 93:859-863.

25. Zhang, Q., Lin, S. C., Zhao, B. Y., Wang, C. L., Yang, W. C., Zhou, Y. L., Li, D. Y., Chen, C. B., and Zhu, L. H. 1998. Identification and tagging a new gene for resistance to bacterial blight (Xanthomonas oryzae pv. oryzae) from O. rufipogon. Rice Genet. Newsl. 15:138-142.

26. Zheng, K. L., Zhuang, J. Y., Lu, J., Qian, H. R., and Lin, H. X. 1996. Identification of DNA markers tightly linked to blast resistance genes in rice. Pages 565-569 in: Rice Genetics III. Proc. Third Int. Rice Genet. Symp. G. S. Khush, ed. International Rice Research Institute, Manila, Philippines. 